\title{
Antiseizure Medication Withdrawal in Seizure-Free Patients: Practice Advisory Update Summary
}

\author{
Report of the AAN Guideline Subcommittee
}

David Gloss, MD, MPH \& TM, Kimberly Pargeon, MD, MA, Alison Pack, MD, Jay Varma, MD, Jacqueline A. French, MD, Benjamin Tolchin, MD, MS, Dennis J. Dlugos, MD, MSCE, Mohamad A. Mikati, MD, Cynthia Harden, MD, on behalf of the AAN Guideline Subcommittee

Neurology ${ }^{\circledR}$ 2021;97:1072-1081. doi:10.1212/WNL.0000000000012944

Correspondence American Academy of Neurology guidelines@aan.com

\section{Abstract}

\section{Objective}

To update a 1996 American Academy of Neurology practice parameter.

\section{Methods}

The authors systematically reviewed literature published from January 1991 to March 2020.

\section{Results}

The long-term (24-60 months) risk of seizure recurrence is possibly higher among adults who have been seizure-free for 2 years and taper antiseizure medications (ASMs) vs those who do not taper ASMs ( $15 \%$ vs $7 \%$ per the 1 Class I article addressing this issue). In pediatric patients, there is probably no significant difference in seizure recurrence between those who begin tapering ASMs after 2 years vs 4 years of seizure freedom, and there is insufficient evidence of significant difference in risk of seizure recurrence between those who taper ASMs after 18 months of seizure freedom and those tapering after 24 months. There is insufficient evidence that the rate of seizure recurrence with ASM withdrawal following epilepsy surgery after 1 year of seizure freedom vs after 4 years is not significantly different than maintaining patients on ASMs. An epileptiform EEG in pediatric patients increases the risk of seizure recurrence. ASM withdrawal possibly does not increase the risk of status epilepticus in adults. In seizure-free adults, ASM weaning possibly does not change quality of life. Withdrawal of ASMs at 25\% every 10 days to 2 weeks is probably not significantly different from withdrawal at $25 \%$ every 2 months in children who are seizure-free in more than 4 years of follow-up.

\section{Recommendations}

Fourteen recommendations were developed. 


\section{Glossary}

AAN = American Academy of Neurology; ASM = antiseizure medication; $\mathbf{C I}=$ confidence interval; $\mathbf{C O I}=$ conflict of interest; GS = Guideline Subcommittee; GTCS = generalized tonic-clonic seizure; HR = hazard ratio; $\mathbf{O R}=$ odds ratio; $\mathbf{R R}=$ relative risk.

Epilepsy is a common disease of the brain and accounts for approximately $1 \%$ of the global burden of all disease. ${ }^{1,2}$ In the United States alone, an estimated 70,000-200,000 adults per year will present with a first unprovoked seizure. ${ }^{3,4}$ The purpose of prescribing an antiseizure medication (ASM) is to render patients with epilepsy seizure-free, a task that is accomplished approximately two-thirds of the time. ${ }^{5,6}$ When seizure freedom is achieved, there is the inevitable question of if and when ASMs should be weaned. Epilepsy is not considered resolved until a patient is seizure-free for at least 10 years and off ASMs for at least the past 5 years. ${ }^{7}$

This practice advisory updates a 1996 American Academy of Neurology (AAN) practice parameter, ${ }^{8}$ which recommended that after assessing the risks and benefits for both patient and society of a recurrent seizure, the discontinuation of ASMs may be considered if the patient meets the following profile:

- Seizure-free 2-5 years while taking ASMs (mean 3.5 years)

- Single type of partial seizure (simple partial or complex partial or secondary generalized tonic-clonic seizure [GTCS]) or single type of primary generalized seizures

- Normal neurologic examination results/normal IQ

- EEG normalized while taking ASMs

A Cochrane review addressed this question in children without generalized seizures but was unable to address this issue in adults or in children with generalized seizures. ${ }^{9}$

The panel for this practice advisory examined questions similar to those addressed in the Cochrane review: For patients with epilepsy taking ASMs who have been seizure-free for at least 12 months, does stopping ASMs, compared with not stopping, do the following?

1. Increase the risk of seizure recurrence (and are there risk factors for seizure recurrence?)

2. Increase the risk of status epilepticus

3. Reduce medication-related side effects

4. Change quality of life

5. Change the risk of mortality

6. Change any of the above risks based on the speed of ASM withdrawal

Data for children were analyzed separately from data for adults because of biological differences in risk of seizure recurrence between the 2 groups. We defined adults as those aged 18 years or older and children as those younger than 18 years. We also distinguished focal (i.e., partial) from generalized seizures because of differences in the underlying mechanism causing epilepsy.

\section{Description of the Analytic Process}

In 2012, the Guideline Subcommittee (GS) of the AAN convened a panel of clinicians with expertise in epilepsy, including content experts (D.G., K.P., J.V., J.A.F., C.H.), a methodologist (D.G.), and GS members (J.A.F., C.H.), to update the 1996 practice parameter, summarized here. In 2020, the GS member B.T. was added to the panel, and 2 content experts with expertise in pediatric neurology, D.J.D. and M.A.M., were added to the panel. The full-length update, including a more detailed description of the analytic process, can be viewed at aan.com/ Guidelines/home/GetGuidelineContent/996.

Each author was required to submit a conflict of interest (COI) form and curriculum vitae, which were reviewed by D.G. and AAN staff for financial and intellectual COIs. The lead developer (D.G.) had no COIs. At project initiation and until September 2018, 1 of the 5 practice advisory developers (J.A.F.) was determined to have relevant COIs. One of the content experts added to the panel in 2020 (D.J.D.) was also determined to have relevant COIs. Neither of these COIs was judged to be significant enough to preclude participation. Both of these judgments were made with the leadership team of the AAN GS. Although one of the developers (C.H.) had no COIs at the time the project was initiated, she accepted a new employment position with Xenon Pharmaceuticals in September 2018. Because of this conflict, she recused herself from further participation on the panel at that time as required by the AAN clinical practice guideline development process manual. ${ }^{10} \mathrm{~A}$ member of the GS with content expertise (A.P.), and no COIs, was appointed to the panel in October 2018 to replace C.H., who is listed as an author because of her contributions before September 2018. After she was recused, the panel continued the development process with internal review of the manuscript, an updated search, a vote on the recommendations, and peer review.

\section{Outcome Criteria}

We addressed the following outcome measures, measured at 12 months or more, comparing those who withdrew from and those continuing taking ASMs:

1. Seizure relapse: These data were divided between children and adults and between those with electroclinical syndromes and epilepsy surgery

2. Risk factors for either higher or lower rates of seizure recurrence that give odds ratios (ORs) at the same time points as measured by the chance of seizure freedom

3. Quality of life data available at the same time points

4. Occurrence of status epilepticus

5. Mortality 


\section{Variables}

We did not prespecify the variables to be considered; instead, we accepted anything the included articles found. We hoped this would be more likely to produce meaningful evidence without prespecified limitations. For any question with 10 or more trials, a funnel plot was preplanned to estimate publication bias.

There was one post hoc decision imposed by the GS after a review of the initial manuscript, in which patient-reported GTCS confirmed by a clinical coordinator would be enough to qualify for Class III, as this would be considered adequate for a reliable patient-reported outcome. All full-text articles were re-reviewed for inclusion due to this post hoc decision.

In April 2013, Medline, CINAHL, DARE, and CENTRAL databases were searched for articles published between January 1991 and April 2013 for relevant peer-reviewed articles that met inclusion criteria, published in English. This search yielded 2,148 articles. In addition, the 17 articles included in the 1996 practice parameter and articles reviewed by the Cochrane review on this topic ${ }^{9}$ were reviewed for inclusion. Of the reviewed abstracts, 154 were identified as potentially relevant and their corresponding articles obtained for full-text review. Each of the 154 articles was reviewed by 2 panel members working independently of each other. Disagreements in article ratings were resolved by discussion. During full text review, there was evidence for an additional question regarding the speed of withdrawal; thus, it was added, and abstracts were re-reviewed. No additional articles were included. The panelists selected 13 articles for inclusion in the analysis. An updated literature search completed in December 2016 identified 106 additional articles, none of which was included. A third literature search was completed in March 2020 to identify articles published since December 2016. Ten additional articles were identified for full text review, but no additional studies were included in this review, as they either did not answer the questions of the guideline or were classified as Class IV.

Selected articles contained information relevant to the 6 questions posed above and had acceptable study designs, including randomized and nonrandomized studies and prospective and retrospective case series published after 1991 that had a control group. We chose to examine studies after 1991 because the 1996 practice parameter did not contain literature beyond this point. Reviews, editorials, and meta-analyses were excluded. Studies of 29 or fewer participants were excluded because any confidence intervals (CIs) formulated from such small studies would not be informative. Also excluded were studies that included fewer than $20 \%$ or an unknown number of patients who have had a single seizure, rather than epilepsy, studies that would be rated as Class IV, studies not relevant to the clinical questions, studies including participants who had unrelated diseases or were outside of the study population, and articles that were not peer-reviewed. Each of the 164 articles was rated by 2 panel members using the AAN criteria for classification of prognosis and treatment. ${ }^{10}$
A modified form of the Grading of Recommendations, Assessment, Development, and Evaluation (GRADE) process was used to develop conclusions. In this process, the evidence is analyzed on the basis of various parameters of risk of bias (multiple types), consistency, directness, precision, and publication bias and upgraded or downgraded according to the AAN process. ${ }^{10}$

The panel followed the AAN process ${ }^{10}$ to formulate a rationale for each of the recommendations. The rationales precede the recommendation statements. According to the AAN process, 4 types of premises can be used to support recommendations: (1) evidence-based conclusions from the systematic review, (2) generally accepted principles of care, (3) strong evidence from related conditions, and (4) deductive inferences from other premises. Recommendations must always be supported by at least one premise. The level of obligation of the recommendations was assigned using a modified Delphi process.

\section{Analysis of Evidence}

\section{For Patients With Epilepsy Taking ASMs Who Have Been Seizure-Free for at Least 12 Months, Does Stopping ASMs Compared With Not Stopping Increase the Risk of Seizure Recurrence, and Are There Risk Factors for Seizure Recurrence?}

\section{Adults}

One Class I study ${ }^{11}$ and 3 Class III studies ${ }^{12-14}$ examined this question. The Class I study ${ }^{11}$ enrolled 160 adults who had been seizure-free for 2 years. Patients were randomized to ASM withdrawal, using placebo, or ASM continuance. The risk of recurrence during the 12 months of the study was not significantly different between the groups: $15 \%$ of the withdrawal group vs $7 \%$ of the nonwithdrawal group experienced seizures following ASM withdrawal (relative risk [RR] 2.46, 95\% CI $0.85-7.08 ; p=0.95$ ). The follow-up portion of the study was Class IV. The risk of seizure recurrence is low compared with other studies with a higher risk of bias.

One Class III study was a nonrandomized, mostly adult, cohort trial in which patients and their caregivers decided whether to withdraw ASMs. ${ }^{12}$ Study participants were patients with epilepsy who were seizure-free for at least 2 years and receiving stable ASM monotherapy. At 60 months, the chance of remaining seizure-free was $68 \%$ (95\% CI 62\%-74\%) among patients who continued treatment and 48\% (95\% CI 38\%-57\%) among patients who did not. During the 60 months of follow-up, after multivariate adjustment, the hazard ratio (HR) for seizure recurrence in patients in whom ASMs were withdrawn was 2.9 (95\% CI 1.8-4.6; $p<0.001)$.

One Class III study randomized 1,013 patients who were seizure-free for at least 2 years to continued ASM treatment vs ASM withdrawal. ${ }^{13}$ The study was included because a majority of seizure recurrences were GTCS (74\%) and, thus, 
considered objective. The study primarily included adults (median age was 26-27 years and medians were presented by group; however, $25 \%$ of patients were aged $16-17$ years at enrollment). Data were not presented separately between adults and children; therefore, the study was used to inform the adult question. The baseline groups were not equivalent. For example, those with a history of attempted ASM withdrawal (OR 0.6, 95\% CI $0.5-0.8 ; p<0.0001)$ as well as those with a driving license were less likely to be randomized (OR $0.13,95 \%$ CI $0.1-0.18$; $p$ $<0.0001$ ), and those with special schooling were more likely to be randomized (OR 5.4, 95\% CI 3.5-9.4; $p<0.0001$ ). Of patients who withdrew ASMs, 43\% (221/510) had a recurrent seizure, compared with $26 \%(133 / 503)$ of patients who continued taking ASMs (OR 2.12, 95\% CI 1.63-2.77; $p<0.0001$ ).

Another Class III study ${ }^{14}$ compared 168 recurrences out of $221(76 \%)$ patients in the withdrawal group and 100 recurrences out of 133 patients (75\%) in the ASM continuation group having multiple recurrences. There was not a statistically significant difference in risk of more than 1 seizure if there was a single recurrence (OR 1.04, 95\% CI $0.63-1.72 ; p<0.86)$.

\section{Conclusions}

In adults who have been seizure-free for 2 years, there is not evidence to support or refute a difference in the rate of seizure recurrence in those who taper ASMs vs those who do not. The point estimate is 2 times greater seizure recurrence in those who taper vs those who do not (15\% vs $7 \%$ ), although this difference is not significantly different. The strength of evidence was downgraded due to imprecision. There were discussions about how to handle the fact that the study had lower risk of seizure recurrence than all other studies, and it was downgraded again for a lack of generalizability because the authors believed that this study represented a different population than is typical (very low confidence, 1 Class I study downgraded for imprecision and generalizability). In the long term (24-60 months), the risk of seizure recurrence is possibly higher among those who taper ASMs (low confidence, 2 Class III studies).

\section{Children}

Two Class II and 2 Class III studies addressed the risk of seizure recurrence after stopping ASMs and risk factors for recurrence in children. In 1 Class II study, 57 patients (mean age 9.5 years) who had seizure control for at least 2 years were tapered either at 2 years or 4 years of seizure freedom. ${ }^{15}$ The Kaplan-Meier survival curve did not demonstrate significant differences in seizure freedom over the 54 months of followup. In the other Class II study, 149 patients (mean age of 11 years) who had been seizure-free for at least 18 months were randomized into tapering at 2 years or 4 years of seizure freedom. ${ }^{16}$ Kaplan-Meier survival curves over the 300 weeks of follow-up were not significantly different between the 2 groups. In the Class III study, patients who had been seizurefree for 18 months were randomized to taper ASMs immediately or to wait an additional 6 months (taper at 24 months).
Of those tapering at 18 months, mean age was 6.7 years. Of those tapering at 24 months, mean age was 5.8 years. ${ }^{17}$ There was no significant difference for seizure recurrence risk during the follow-up period. During follow-up, 12 of 41 (29\%) patients who tapered at 18 months had seizure recurrence during their 38 months of mean follow-up; 14 of 39 (36\%) who tapered at 24 months had recurrence during their 24 months of mean follow-up, yielding an RR of 0.82 (95\% CI $0.43-1.534$ ). A second Class III study of 238 children (mean age of 8.8 years) were randomized to treatment for 1 or 3 years; both groups were followed for 5 years. ${ }^{18}$ After correcting for multiple comparisons (Bonferroni correction), there were no significant differences in the percentage of children seizure-free during the last 6 months of observation ( $72 \%$ vs $84 \%$, RR $0.857,95 \%$ CI $0.740-0.991 ; p>0.05$ ) or the entire follow-up period ( $32 \%$ vs $41 \%$, RR $0.775,95 \%$ CI $0.539-1.115 ; p>0.05$ ). In this trial, $8 \%$ of children continued to have some seizures with treatment, and $2 \%$ became medication resistant, which was defined as more than 1 seizure per month.

\section{Conclusions}

There is probably not a significant difference in seizure recurrence in children who taper ASMs at 2 vs 4 years (time of seizure freedom) (moderate confidence in evidence, 2 Class II studies). There is insufficient evidence whether there is a significant difference in the risk of seizure recurrence in children who taper ASMs at 18 vs 24 months (very low confidence, 1 Class III study).

\section{Electroclinical Syndromes}

Electroclinical syndromes have some or all of the following characteristics: specified age range at onset, specific developmental changes, specific physical characteristics, specific seizure provoking/triggering factors, and specific EEG features. ${ }^{19}$ None of the included studies with ratings higher than Class IV addressed the question of drug withdrawal and risk of seizure recurrence in specific electroclinical syndromes.

\section{Epilepsy Surgery}

A single Class III study addressed the question of drug withdrawal and risk of seizure recurrence in patients who had undergone epilepsy surgery. ${ }^{20}$ This study did not demonstrate significant differences at 1 and 4 years in maintaining seizure freedom between patients who had surgery, were seizure-free for at least a year, and tapered ASMs and those who had surgery, were seizure-free for at least 1 year, and continued taking ASMs (31/34 [91\%] vs 20/26 [77\%], respectively; RR 1.185 , 95\% CI 0.937-1.499; $p>0.05$ ).

\section{Conclusion}

There is insufficient evidence to support or refute that the rate of seizure recurrence at 1 vs 4 years in patients who have undergone epilepsy surgery who discontinue ASMs is not significantly different from the rates in patients who continue taking ASMs (very low confidence, 1 Class III study). 


\section{Risk Factors for Seizure Recurrence: Adults}

Of the Class III studies, one study was in a mixed cohort of mostly adults. ${ }^{12}$ In this study, the following factors were associated with a significantly increased odds of seizure recurrence: 2 years of seizure freedom at study entry, compared with longer times of seizure freedom (OR 2.6, 95\% CI 1.5-4.8; $p<0.001$ ), and abnormal psychiatric examination results (OR 2.1, 95\% CI 1.3-3.6; $p<0.004$ ). Duration of active disease, epilepsy syndrome, and abnormal CT/MRI results were not significant factors for an increased risk of seizure recurrence.

One Class III study looked at whether there was a difference among ASMs. ${ }^{21}$ This study found that monotherapy with valproate, phenobarbitone and primidone, or phenytoin was associated with a significant risk of seizure recurrence following ASM withdrawal (HR 1.97, 95\% CI 1.29-3.0; $p<0.004$; HR 3.55, 95\% CI 1.24-10.2; $p<0.02$; and HR 3.02, 95\% CI 1.84-4.97; $p<0.001$, respectively). This was not true for carbamazepine (HR 1.32, 95\% CI 0.85-2.0). A second Class III study created a risk index for seizure recurrence. ${ }^{22}$ Using a Cox proportional hazards regression, the authors found 7 prognostic factors for increased risk of seizures: age 16 years or older (RR 1.75, 95\% CI 1.30-2.35), use of more than 1 ASM (RR 1.83, 95\% CI 1.40-2.39), history of seizures after starting an ASM (RR 1.56, 95\% CI 1.19-2.04), history of tonic-clonic seizures (RR 1.56, 95\% CI 1.09-2.22), history of myoclonic seizures (RR 1.84, 95\% CI 1.13-3.01), and an abnormal EEG in the past year (RR 1.32, 95\% CI 1.01-1.73).

\section{Risk Factors for Seizure Recurrence: Children}

Three Class III prognostic studies in children were identified. One ${ }^{17}$ found that an abnormal EEG before discontinuation was associated with seizure recurrence in children (RR 6.21, 95\% CI 5.62-68.5 [CI as given in article]). An abnormal EEG was defined as one with spikes, sharp waves, paroxysmal slowing, or nonparoxysmal abnormalities. Two Class III prognostic studies in the same cohort were identified. ${ }^{23,24}$ The first ${ }^{23}$ considered more than 20 factors; after Bonferroni correction, there were no statistically significant factors. The second ${ }^{24}$ looked more specifically at EEG and found that among both groups of children (1-year and 3-year withdrawal), there was a higher risk of seizure recurrence in children with interictal epileptiform activity on the EEG (24 of 51 with epileptiform activity [47\%] vs 31 of 94 without interictal epileptiform activity [33\%]), yielding an OR of 2.87 (95\% CI 1.35-6.11; $p=0.006$ ).

\section{Conclusions}

Interictal epileptiform activity on EEG possibly increases the risk of seizure recurrence in children (low confidence, 2 Class III studies). Except for an epileptiform EEG, there is insufficient evidence to support or refute that a variety of risk factors predict a different chance of seizure recurrence (very low confidence, 1 Class I study in adults downgraded due to imprecision and generalizability). Neither of the included studies specified what kind of EEG was performed (e.g., length of study, sleep deprived); thus, we are unable to determine what length of EEG is needed to assess seizure recurrence risk.

For Patients With Epilepsy Who Take ASMs and Who Have Been Seizure-Free for at Least 12 Months, Does Stopping ASMs, Compared With Not Stopping, Increase the Risk of

\section{Status Epilepticus?}

One Class I study addressed this question. ${ }^{11}$ It did not find any significant predictors for the risk of status epilepticus (after Bonferroni correction); the study authors looked at age, sex, age at epilepsy onset, focal (partial) vs generalized epilepsy, MRI findings, duration of seizure freedom, specific ASMs, and a normal neurologic examination result.

No patients in the ASM withdrawal arm of the 1-year adult Class I randomized controlled trial had status epilepticus. ${ }^{11}$ Most studies did not specifically mention any information about this.

\section{Conclusion}

ASM withdrawal possibly may not increase the risk of status epilepticus in adults (low confidence, 1 Class I study, lowered due to imprecision).

\section{For Patients With Epilepsy Taking ASMs Who Have Been Seizure-Free for at Least 12 Months, Does Stopping ASMs, Compared to Not Stopping, Reduce Medication-Related Side Effects?}

There were no studies higher than Class IV that addressed this question.

\section{For Patients With Epilepsy Taking ASMs Who Have Been Seizure-Free for at Least 12 Months, Does Stopping ASMs, Compared to Not Stopping, Change Quality of Life?}

There was 1 Class I study that addressed this question. ${ }^{11}$ It did not find significant differences in 3 quality of life measures, including the Quality of Life in Epilepsy Inventory-89 (mean score difference $0.3,95 \% \mathrm{CI}-1.55$ to 2.07 ), between patients who withdrew ASMs and those who did not.

\section{Conclusion}

In adults who are seizure-free, ASM weaning possibly does not change quality of life (low confidence, 1 Class I study, downgraded due to data imprecision).

For Patients With Epilepsy Taking ASMs Who Have Been Seizure-Free for at Least 12 Months, Does Stopping ASMs, Compared to Not Stopping, Change the Risk of Mortality?

Only 2 studies specifically discussed mortality. During the 1 -year adult Class I trial of ASM withdrawal, there were no deaths. ${ }^{11}$ During the 6 years of follow-up of a Class III study, ${ }^{13} 2$ patients who continued ASMs died, most likely from a seizure.

\section{Conclusion}

There is insufficient evidence to support or refute that ASM withdrawal may change the risk of mortality in adults because 
there were no deaths in either arm of the trial (low confidence, 1 Class I and 1 Class III study, downgraded due to imprecision).

\section{For Patients With Epilepsy Taking ASMs Who} Have Been Seizure-Free for at Least 12 Months, Does Stopping ASMs, Compared With Not Stopping, Change the Risk of Seizure Recurrence Based on the Speed of Medication Withdrawal?

Two Class II studies addressed this question in children. In 1 Class II study, 57 patients tapered ASMs by $25 \%$ every 10 days or $25 \%$ every 2 months. ${ }^{15}$ Kaplan-Meier survival curves over 54 months of follow-up were not significantly different between groups. In the other Class II study, ASMs were tapered at a rate of $25 \%$ every 2 weeks or $25 \%$ every 2 months. ${ }^{16}$ No significant differences were present in the Kaplan-Meier survival curves across the 300 weeks of follow-up.

\section{Conclusion}

In children who are seizure-free, withdrawal of ASMs at a rate of $25 \%$ every 10 days to 2 weeks is probably not significantly different in risk of seizure recurrence than withdrawal at a rate of $25 \%$ every 2 months throughout more than 4 years of follow-up (moderate confidence, 2 Class II trials).

\section{Practice Recommendations}

\section{Recommendations Related to Adults}

\section{Recommendation 1 Rationale}

There is low confidence that the risk of seizure recurrence is significantly higher among patients with a history of seizures who have been seizure-free over 24-60 months who taper ASMs when compared with patients who do not taper ASMs. Once epilepsy is masked, it is unknowable if the patient continues to have epilepsy or not. Patients should be part of the medical decision-making process, especially when there is clinical equipoise.

Although there is evidence for the predictive power of epileptiform abnormality in EEGs in children, there is no evidence above Class IV in adults. Moreover, the evidence in children cannot be used as related evidence in adults, as it is based on Class III data. The same applies for the small chance of medication resistance seen after ASM withdrawal.

To enable patients to make decisions, all the clinically relevant information should be made available. There are multiple factors in making this decision:

- Low-quality evidence suggests no difference in quality of life between patients with well-controlled epilepsy who stop vs continue taking ASMs.

- Factors contributing to quality of life are potentially highly individual and may include ease of ASM administration (e.g., dose frequency), experience of side effects, seizure recurrence, and comorbidities.

- In the 1-year follow-up of 1 trial, there were no deaths, and in the 6-year follow-up of the other trial, the only deaths that occurred were in patients who continued taking ASMs. There does not seem to be an increased risk of status epilepticus in patients who are seizure-free for 2 years who withdrew ASMs; however, the risk of status epilepticus may be small in the cohorts of the study, and there may not be enough patients and time to detect a difference. There is no evidence that 2 years has special significance. It is well known that status epilepticus is a cause of mortality in epilepsy. ${ }^{25}$

\section{Recommendation Statement 1a}

In adults who are seizure-free for at least 2 years, there should be a discussion between the clinician and the patient or caregiver, if any, about the risks and benefits of ASM withdrawal, which specifically includes and documents that:

1. There is possibly higher seizure recurrence in patients who had ASM withdrawal; and

2. If seizures recur during or after withdrawal, there is a small chance they will no longer respond to medications (Level B)

\section{Recommendation Statement $\mathbf{1 b}$}

When discussing either ASM withdrawal or continuation with patients, because there is no statistically significant evidence to support either option, clinicians may consider individual patient characteristics and preferences (Level C).

\section{Recommendation Statement 1c}

Counseling must include discussion that there is not strong evidence regarding the relationship between ASM withdrawal and changes in the risk of mortality and status epilepticus, and, as such, these risks have not been excluded by the evidence (Level A).

\section{Recommendation Statement 1d}

Clinicians should counsel that recurrent seizures put people at risk for status epilepticus and death (Level B), although existing data do not suggest an increased risk of status epilepticus or death after ASM withdrawal.

\section{Recommendation Statement 1e}

Clinicians must explore contributors to the quality of life of individual patients as part of shared decision-making regarding ASM discontinuation (Level A).

\section{Recommendation Statement $\mathbf{1 f}$}

Clinicians should discuss with seizure-free patients that it is unknown if EEG or imaging studies inform the decision to withdraw ASMs (Level B).

\section{Recommendation 2 Rationale}

There is only 1 low-quality trial that examines the relationship between epilepsy surgery and ASM withdrawal, and no conclusions can be drawn from the trial.

\section{Recommendation Statement 2}

Clinicians may discuss that the risk of seizure recurrence with ASM withdrawal in patients who have had epilepsy surgery 
and are seizure-free is uncertain due to the lack of evidence (Level C).

\section{Recommendations Related to Children}

\section{Recommendation 3 Rationale}

There does not appear to be a statistically significant difference when ASMs are withdrawn in pediatric patients who have been seizure-free for 2 years vs 4 years when patients have been seizure-free for 18-24 months during the first 4-6 years of follow-up. While the cohorts were broad, they do not include large numbers of children with electroclinical syndromes. When there is no significant difference between treatment and lack of treatment over long periods of time, lack of treatment may be the preferred option. There is a small risk of becoming medication resistant with ASM withdrawal.

There is low confidence in evidence that an epileptiform EEG increases the risk of recurrence of seizures in children.

Patients and families of children who are seizure-free and contemplating ASM withdrawal would want any information about the withdrawal process that is available. The evidence suggests there is not a significant difference between weaning $25 \%$ every 10 days to 2 weeks vs 2 months.

\section{Recommendation Statement 3a}

In children who are seizure-free for at least 18-24 months, who do not have an electroclinical syndrome suggesting otherwise, there should be a discussion about the risks and benefits of ASM withdrawal that specifically includes and documents that if seizures recur during either withdrawal or after withdrawal, there is a small chance they will no longer respond to medication (Level B).

\section{Recommendation Statement 3b}

Clinicians should discuss with children and their families that ASM withdrawal can be considered because withdrawal of ASMs does not clearly increase risk of seizure recurrence (Level B).

\section{Recommendation Statement 3c}

Clinicians should counsel that recurrent seizures put children at risk for status epilepticus and death (Level B), although existing data do not suggest an increased risk of status epilepticus or death after ASM withdrawal.

\section{Recommendation Statement 3d}

Clinicians should explore contributors to quality of life for individual patients as part of shared decision-making regarding ASM withdrawal (Level B).

\section{Recommendation Statement $3 e$}

In children seizure-free for at least 18-24 months, if there is agreement among the physician, patient, and family to pursue consideration of ASM withdrawal, an EEG should be ordered (Level B).

\section{Recommendation Statement $3 \mathbf{f}$}

In children seizure-free for at least 18-24 months, in whom there is agreement among the physician, patient, and family to pursue consideration of ASM withdrawal, if the EEG does not show epileptiform activity, ASM withdrawal should be offered, at a rate no faster than $25 \%$ every $10-14$ days (Level B).

\section{Recommendation Statement $\mathbf{3 g}$}

Clinicians must take into account the known natural history of the specific electroclinical syndrome when counseling about ASM withdrawal in children (Level A [no low to moderate risk of bias evidence]).

\section{Suggestions for Future Research}

Future areas of study include the many gaps shown by this guideline. High-quality studies that answer the following questions and address the following statements are needed:

1. Is an EEG, or a modern MRI, or any genetic testing result a relevant prognostic factor in ASM withdrawal? Is there a specific kind of EEG, or other qualitative properties of the EEG, that is optimal?

2. Is there a certain speed of ASM withdrawal in adults that should be recommended?

3. Are there additional risks for people who experience recurrent seizures after ASM withdrawal? Should a different period of seizure freedom be considered, or be considered at all, before a second ASM withdrawal is attempted?

4. Are there specific electroclinical syndromes (e.g., absence epilepsy, juvenile myoclonic epilepsy) that should or should not preclude consideration of ASM withdrawal?

5. More data are needed to address the rate of taper.

6. There is no current evidence to support the use of online seizure prediction tools. High-quality data are needed to demonstrate their validity.

7. Data about driving and ASM withdrawal and safety are needed.

Ideally a registry or consortia could be formed that could have cohorts large enough to examine whether there are additional risks of status epilepticus or mortality or differences between adults and children.

\section{Conflict of Interest}

The AAN is committed to producing independent, critical, and truthful clinical practice guidelines (CPGs). Significant efforts are made to minimize the potential for conflicts of interest to influence the recommendations of this CPG. To the extent possible, the AAN keeps separate those who have a financial stake in the success or failure of the products appraised in the CPGs and the developers of the guidelines. Conflict of interest forms were obtained from all authors and reviewed by an oversight committee prior to project initiation. The AAN limits the participation of authors with substantial 
conflicts of interest. The AAN forbids commercial participation in, or funding of, guideline projects. Drafts of the guideline have been reviewed by at least 3 AAN committees, a network of neurologists, Neurology peer reviewers, and representatives from related fields. The AAN Guideline Author Conflict of Interest Policy can be viewed at aan.com. For complete information on this process, access the 2011 AAN process manual, as amended. ${ }^{10}$

\section{Disclaimer}

Clinical practice guidelines, practice advisories, comprehensive systematic reviews, focused systematic reviews, and other guidance published by the AAN and its affiliates are assessments of current scientific and clinical information provided as an educational service. The information (1) should not be considered inclusive of all proper treatments, methods of care, or as a statement of the standard of care; (2) is not continually updated and may not reflect the most recent evidence (new evidence may emerge between the time information is developed and when it is published or read); (3) addresses only the question(s) specifically identified; (4) does not mandate any particular course of medical care; and (5) is not intended to substitute for the independent professional judgement of the treating provider, as the information does not account for individual variation among patients. In all cases, the selected course of action should be considered by the treating provider in the context of treating the individual patient. Use of the information is voluntary. The AAN provides this information on an "as is" basis, and makes no warranty, expressed or implied, regarding the information. The AAN specifically disclaims any warranties of merchantability or fitness for a particular use or purpose. The AAN assumes no responsibility for any injury or damage to persons or property arising out of or related to any use of this information or for any errors or omissions.

\section{Study Funding}

This practice guideline was developed with financial support from the American Academy of Neurology (AAN). Authors who serve or have served as AAN subcommittee members or as methodologists (D.G., A.P., J.A.F., B.T., and C.H.) were reimbursed by the AAN for expenses related to travel to subcommittee meetings where drafts of manuscripts were reviewed. All authors on the panel were reimbursed by the AAN for expenses related to travel to in-person meetings.

\section{Disclosure}

Dr. Gloss and Dr. Pargeon report no relevant disclosures. Dr. Pack served on the editorial board of Epilepsy Currents; receives royalties from UpToDate; receives funding from the NIH for serving as coinvestigator and site principal investigator for the Maternal Outcomes and Neurodevelopmental Effects of Antiepileptic Drugs (MONEAD) study; received funding from Bayer for serving as a coinvestigator on a study on women with epilepsy initiating a progestin IUD; and her husband serves as the CMO for Regenxbio, for which he receives salary and stock options. Dr. Varma reports no relevant disclosures. Dr. French receives NYU salary support from the Epilepsy Foundation and for consulting work and/or attending Scientific Advisory Boards on behalf of the Epilepsy Study Consortium for Adamas, Aeonian/Aeovian, Anavex, Arkin Holdings, Arvelle Therapeutics, Inc., Athenen Therapeutics/Carnot Pharma, Baergic Bio, Biogen, BioXcel Therapeutics, Cavion, Cerebral Therapeutics, Cerevel, Crossject, CuroNZ, Eisai, Eliem Therapeutics, Encoded Therapeutics, Engage Therapeutics, Engrail, Epiminder, Equilibre BioPharmaceuticals, Fortress Biotech, Greenwich Biosciences, GW Pharma, Janssen Pharmaceutica, Knopp Biosciences, Lundbeck, Marinus, Mend Neuroscience, Merck, NeuCyte, Inc., Neurocrine, Otsuka Pharmaceutical Development, Ovid Therapeutics Inc., Passage Bio, Praxis, Redpin, SAGE, SK Life Sciences, Sofinnova, Stoke, Supernus, Synergia Medical, Takeda, UCB Inc., West Therapeutic Development, Xenon, Xeris, Zogenix, and Zynerba; has received research support from the Epilepsy Research Foundation, Epilepsy Study Consortium (funded by Andrews Foundation, Eisai, Engage, Lundbeck, Pfizer, SK Life Science, Sunovion, UCB, and Vogelstein Foundation), Epilepsy Study Consortium/Epilepsy Foundation (funded by UCB, Engage, Neurelis, and SK Life Science), GW/One8 Foundation/ FACES, and NINDS; is on the editorial board of Lancet Neurology and Neurology Today; is Chief Medical/Innovation Officer for the Epilepsy Foundation, for which NYU receives salary support; and has received travel reimbursement related to research, advisory meetings, or presentation of results at scientific meetings from the Epilepsy Study Consortium, the Epilepsy Foundation, Arvelle Therapeutics, Inc., Biogen, Cerevel, Engage, Lundbeck, NeuCyte, Inc., Otsuka, Sage, UCB, Xenon, and Zogenix. Dr. Tolchin has received research funding from the Department of Veterans Affairs, the C.G. Swebilius Trust, and the American Academy of Neurology and has received honoraria from Columbia University Medical Center and the International League Against Epilepsy. Dr. Dlugos receives travel reimbursement for protocol development conferences and clinical trial investigator meetings from Marinus, Ovid/Takeda, Ultragenyx, Pfizer, Biogen, BioMarin, and Xenon; receives research funding for serving as site investigator on clinical trial research grants awarded to CHOP from Zogenix, Greenwich Biosciences, Brain Sentinel, Neurelis, Q-State, Aquestive, Bio-Pharm, SK Life Sciences, and Encoded Therapeutics; has received honoraria and/or travel support for CME and other educational programs from Wake Forest University School of Medicine, American Epilepsy Society, American Academy of Neurology, Epilepsy Foundation of America, Epilepsy Foundation of North Carolina, Medscape, Miller Medical Communications, Ecuador Neurology Project, Ministry of Health of the United Arab Emirates, Seoul National University, and the Chinese Pediatric Society; performs EEGs as 20\% of clinical effort (clinical effort is only 25\% of work); and receives salary support from NIH, Commonwealth of Pennsylvania Department of Health, Pediatric Epilepsy Research Foundation, and The Epilepsy Study Consortium. M.A. Mikati holds a pending patent for gene therapy of ATPase-related diseases, including hemiplegia of childhood; serves on editorial boards of 
the following journals: Annals of Neurology, Epileptic Disorders, and Epilepsy Research; has received travel reimbursement from AHRQ for travel to Cure AHC conferences; receives royalties (about $\$ 50$ per year) from Springer for a developmental pediatrics textbook; spends an estimated $20 \%$ of clinical effort ordering and reading EEGs; has received research support from $\mathrm{NIH}$ for a study on which he serves as a consultant, NIH 2036303 (2014-2022): Undiagnosed Diseases Network Clinical Site, an integrated and diverse genomic medicine program for undiagnosed diseases, a study to detect genetic etiologies in patients with disorders of undiagnosed conditions; and has reviewed a medico-legal case regarding an intracranial bleed in an infant. Dr. Harden receives royalties from UpToDate and Wiley; serves on the speakers' bureau for UBC; and has received research support from NINDS of the NIH and the Epilepsy Therapy Project. In September 2018, Dr. Harden accepted a new employment position with Xenon Pharmaceuticals and recused herself from further participation on the panel. Prior to accepting the employment position, Dr. Harden contributed to the development of this guideline, therefore she is listed as an author. After she was recused, the panel continued the development process with internal review of the manuscript, an updated search, a vote on the recommendations, and peer review. Go to Neurology.org/ $\mathrm{N}$ for full disclosures.

\section{Publication History}

Received by Neurology November 15, 2019. Accepted in final form September 24, 2021.

\section{Appendix Authors}

\begin{tabular}{|c|c|c|}
\hline Name & Location & Contribution \\
\hline $\begin{array}{l}\text { David } \\
\text { Gloss, MD, } \\
\text { MPH \& TM }\end{array}$ & $\begin{array}{l}\text { Department of Neurology, } \\
\text { Charleston Area Medical } \\
\text { Center, WV }\end{array}$ & $\begin{array}{l}\text { Study concept and design, } \\
\text { acquisition of data, } \\
\text { analysis or interpretation } \\
\text { of data, drafting/revising } \\
\text { the manuscript, critical } \\
\text { revision of the manuscript } \\
\text { for important intellectual } \\
\text { content, study supervision }\end{array}$ \\
\hline
\end{tabular}

\begin{tabular}{ll}
\hline Kimberly & Department of Neurology, \\
Pargeon, & Harbor-UCLA Medical Center, \\
MD, MA & Torrance, CA
\end{tabular}

Study concept and design, acquisition of data, analysis or interpretation of data, drafting/revising the manuscript

\begin{tabular}{lll}
\hline Alison & Columbia University, & Drafting/revising the \\
Pack, MD & New York, NY & manuscript, study \\
& & supervision
\end{tabular}

Jay Varma, Department of Neurology, MD Barrow Neurological Institute, Phoenix, AZ

Study concept and design, acquisition of data, analysis or interpretation of data, drafting/revising the manuscript

\begin{tabular}{lll}
\hline Jackie & Department of Neurology, & Study concept and design, \\
French, MD & New York University Grossman & acquisition of data, \\
School of Medicine and NYU & analysis or interpretation \\
Langone Health, NY & of data, drafting/revising \\
& the manuscript, critical \\
& revision of the manuscript \\
& for important intellectual \\
& content, study supervision
\end{tabular}

Appendix (continued)

\begin{tabular}{|c|c|c|}
\hline Name & Location & Contribution \\
\hline $\begin{array}{l}\text { Benjamin } \\
\text { Tolchin, } \\
\text { MD, MS }\end{array}$ & $\begin{array}{l}\text { Department of Neurology, Yale } \\
\text { University School of Medicine, } \\
\text { New Haven, CT }\end{array}$ & $\begin{array}{l}\text { Drafting/revising the } \\
\text { manuscript }\end{array}$ \\
\hline $\begin{array}{l}\text { Dennis J. } \\
\text { Dlugos, } \\
\text { MD, MSCE }\end{array}$ & $\begin{array}{l}\text { Departments of Neurology and } \\
\text { Pediatrics, Children's Hospital } \\
\text { of Philadelphia, Perelman } \\
\text { School of Medicine at the } \\
\text { University of Pennsylvania, } \\
\text { Philadelphia }\end{array}$ & $\begin{array}{l}\text { Drafting/revising the } \\
\text { manuscript }\end{array}$ \\
\hline $\begin{array}{l}\text { Mohamad } \\
\text { A. Mikati, } \\
\text { MD }\end{array}$ & $\begin{array}{l}\text { Departments of Pediatrics and } \\
\text { Neurobiology, Duke University } \\
\text { Medical Center, Durham, NC }\end{array}$ & $\begin{array}{l}\text { Drafting/revising the } \\
\text { manuscript }\end{array}$ \\
\hline $\begin{array}{l}\text { Cynthia } \\
\text { Harden, } \\
\text { MD }\end{array}$ & $\begin{array}{l}\text { Xenon Pharmaceuticals, } \\
\text { Burnaby, Canada }\end{array}$ & $\begin{array}{l}\text { Study concept and design, } \\
\text { acquisition of data, } \\
\text { analysis or interpretation } \\
\text { of data, drafting/revising } \\
\text { the manuscript, } \\
\text { critical revision of the } \\
\text { manuscript for important } \\
\text { intellectual content, study } \\
\text { supervision }\end{array}$ \\
\hline
\end{tabular}

\section{References}

1. Murray CJL, Lopez AD. Global Comparative Assessment in the Health Sector. World Health Organization; 1994.

2. GBD 2015 Neurological Disorders Collaborator Group. Global, regional, and national burden of neurological disorders during 1990-2015: a systemic analysis for the Global Burden of Disease Study 2015. Lancet Neurol 2017;16(11):877-897.

3. Hauser WA, Annegers JF, Kurland LT. Incidence of epilepsy and unprovoked seizures in Rochester, Minnesota: 1935-1984. Epilepsia 1993;34(3):453-468.

4. Hauser WA, Beghi E. First seizure definitions and worldwide incidence and mortality. Epilepsia 2008;49(suppl 1):s8-s12.

5. Kwan P, Brodie MJ. Early identification of refractory epilepsy. N Engl J Med 2000; 342(5):314-319.

6. Mohanraj R, Brodie MJ. Diagnosing refractory epilepsy: response to sequential treatment schedules. Eur J Neurol 2006;13(3):277-282.

7. Fisher RS, Acevedo C, Arzimanoglou A, et al. ILAE official report: a practical clinical definition of epilepsy. Epilepsia 2014;55(4):475-482.

8. American Academy of Neurology. A guideline for discontinuing antiepileptic drugs in seizure-free patients-summary statement. Neurology 1996;47(2):600-602.

9. Sirven JI, Sperling MR, Wingerchuk DM. Early versus late antiepileptic drug withdrawal for people with epilepsy in remission. Cochrane Database Syst Rev 2001;3: CD001902.

10. American Academy of Neurology. Clinical Practice Guideline Process Manual. American academy of Neurology; 2011.

11. Lossius MI, Hessen E, Mowinckel P, et al. Consequences of antiepileptic drug withdrawal: a randomized, double-blind study (Akershus Study). Epilepsia 2008; 49(3):455-463.

12. Specchio LM, Tramacere L, La Neve A, Beghi E. Discontinuing antiepileptic drugs in patients who are seizure free on monotherapy. J Neurol Neurosurg Psychiatry 2002; 72(1):22-25.

13. Randomised study of antiepileptic drug withdrawal in patients in remission. Medical Research Council Antiepileptic Drug Withdrawal Study Group. Lancet 1991; 337(8751):1175-1180

14. Chadwick D, Taylor J, Johnson T. Outcomes after seizure recurrence in people with well-controlled epilepsy and the factors that influence it. Epilepsia 1996;37(11): 1043-1050.

15. Serra JG, Montenegro MA, Geurreiro MM. Antiepileptic drug withdrawal in childhood: does the duration of tapering off matter for seizure recurrence? J Child Neurol 2005;20(7):624-626

16. Tennison M, Greenwood R, Lewis D, Thorn M. Discontinuing antiepileptic drugs in children with epilepsy: a comparison of a six-week and a nine-month taper period. N Engl J Med 1994;330(20):1407-1410.

17. Gebremariam A, Mengesha W, Enqusilassie F. Discontinuing anti-epileptic medication(s) in epileptic children: 18 versus 24 months. Ann Trop Paediatr 1999;19(1): 93-99.

18. Braathan G, Andersson T, Gylje H, et al. Comparison between one and three years of treatment in uncomplicated childhood epilepsy: a prospective study: I: outcome in different seizure types. Epilepsia 1996;37(9):822-832.

19. Berg AT, Berkovic SF, Brodie MJ, et al. Revised terminology and concepts for organization of seizure and epilepsies: report of the ILAE Commission on Classification and Terminology, 2005-2009. Epilepsia 2010;51(4):676-685. 
20. Kerling F, Pauli E, Lorber B, Blumcke I, Buchfelder M, Stefan H. Drug withdrawal after successful epilepsy surgery: how safe is it? Epilepsy Behav 2009;15(4):476-480.

21. Chadwick D. Does withdrawal of different antiepileptic drugs have different effects on seizure recurrence? Further results from the MRC Antiepileptic Drug Withdrawal Study. Brain 1999;122(pt 3):441-448

22. Medical Research Council Antiepileptic Drug Withdrawal Study Group. Prognostic index for recurrence of seizures after remission of epilepsy.BMJ 1993;306(6889): 1374-1378.
23. Braathen G, Melander H. Early discontinuation of treatment in children with uncomplicated epilepsy: a prospective study with a model for prediction of outcome. Epilepsia 1997;38(5):561-569.

24. Andersson T, Braathen G, Persson A, Theorell K. A Comparison between one and three years of treatment in uncomplicated childhood epilepsy: a prospective study: II: the EEG as predictor of outcome after withdrawal of treatment. Epilepsia 1997;38(2):225-232.

25. Ristić AJ, Sokić DV, Trajković G, et al. Long-term survival in patients with status epilepticus: a tertiary referral center study. Epilepsia 2010;51(1):57-61.

\section{Subspecialty Alerts by E-mail!}

Customize your online journal experience by signing up for e-mail alerts related to your subspecialty or area of interest. Access this free service by clicking on the "My Alerts" link on the home page. An extensive list of subspecialties, methods, and study design choices will be available for you to choose from-allowing you priority alerts to cutting-edge research in your field!

\section{Call for Biostatisticians to peer review for Neurology ${ }^{\circledR}$}

We are seeking qualified experts to review the biostatistical aspects of submitted articles. We welcome those specializing in biostatistics with a background in experimental design and the review of randomized clinical trials, observational studies, genetic studies, and imaging studies in the neurodegenerative diseases.

If interested, please send CV to the Neurology Editorial Office: journal@neurology.org.

\section{Visit the Neurology ${ }^{\circledR}$ Resident \& Fellow Website}

Click on Residents \& Fellows tab at Neurology.org.

Now offering:

- Neurology Resident \& Fellow Editorial team information

- "Search by subcategory" option

- E-Pearl of the Week

- Direct links to Career Planning and AAN Resident \& Fellow Pages

- Recently published Resident \& Fellow articles

- Commentaries by Editors and Resident \& Fellow team members

f Find Neurology Residents \& Fellows Section on Facebook: facebook.com/AANResidentsAndFellows

Follow Neurology on Twitter: @GreenJournal \#NeurologyRF

(ㄱ) Find Neurology Residents \& Fellows Section on Instagram: @aanbrain \#NeurologyRF 


\title{
Neurology
}

\author{
Antiseizure Medication Withdrawal in Seizure-Free Patients: Practice Advisory Update \\ Summary: Report of the AAN Guideline Subcommittee \\ David Gloss, Kimberly Pargeon, Alison Pack, et al. \\ Neurology 2021;97;1072-1081 \\ DOI 10.1212/WNL.0000000000012944
}

\section{This information is current as of December 6, 2021}

\section{Updated Information \& Services}

References

Citations

Subspecialty Collections

Permissions \& Licensing

Reprints including high resolution figures, can be found at: http://n.neurology.org/content/97/23/1072.full

This article cites 23 articles, 3 of which you can access for free at: http://n.neurology.org/content/97/23/1072.full\#ref-list-1

This article has been cited by 4 HighWire-hosted articles: http://n.neurology.org/content/97/23/1072.full\#\#otherarticles

This article, along with others on similar topics, appears in the following collection(s):

All Epilepsy/Seizures

http://n.neurology.org/cgi/collection/all_epilepsy_seizures

Antiepileptic drugs

http://n.neurology.org/cgi/collection/antiepileptic_drugs

Class I

http://n.neurology.org/cgi/collection/class_1

EEG

http://n.neurology.org/cgi/collection/eeg_

Status epilepticus

http://n.neurology.org/cgi/collection/status_epilepticus

Information about reproducing this article in parts (figures,tables) or in its entirety can be found online at:

http://www.neurology.org/about/about_the_journal\#permissions

Information about ordering reprints can be found online:

http://n.neurology.org/subscribers/advertise

Neurology ${ }^{\circledR}$ is the official journal of the American Academy of Neurology. Published continuously since 1951, it is now a weekly with 48 issues per year. Copyright (C 2021 American Academy of Neurology. All rights reserved. Print ISSN: 0028-3878. Online ISSN: 1526-632X.

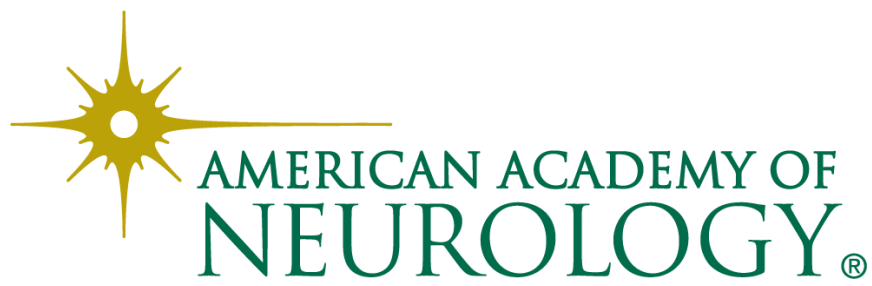

